\title{
Shaming, Blaming, and Responsibility
}

\author{
Lucy McDonald \\ St John's College, University of Cambridge, Cambridge, United Kingdom \\ Im675@cam.ac.uk
}

\begin{abstract}
Despite its cultural prominence, shaming has been neglected in moral philosophy. I develop an overdue account of shaming, which distinguishes it from both blaming and the mere production of shame. I distinguish between two kinds of shaming. Agential shaming is a form of blaming. It involves holding an individual morally responsible for some wrongdoing or flaw by expressing a negative reactive attitude towards her and inviting an audience to join in. Non-agential shaming also involves negatively evaluating a person and inviting an audience to join in. Yet it is not a form of blaming, because the shamer does not hold the target morally responsible for anything. For example, we non-agentially shame people for their body shapes, for having periods, or for being victims of rape. Non-agential shaming involves the expression of an emotionally toned objective attitude, like disgust. While agential shaming enforces social norms, non-agential shaming enforces social standards.
\end{abstract}

\section{Keywords}

blame - reactive attitudes - responsibility - shame - shaming

Shaming is in vogue. It is the subject of several best-selling books, and every day we encounter news stories and social media posts about 'slut-shaming,' 'body-shaming,' and 'mom-shaming.' ${ }^{\prime}$ Sometimes shaming is subjected to hand-wringing over its dangerous consequences, and other times it is encouraged, with demands that perpetrators of wrongdoing be 'named and

1 See Jon Ronson, So You've Been Publicly Shamed (London: Picador, 2015) and Jennifer Jacquet, Is Shame Necessary?: New Uses for an Old Tool (London: Penguin Books, 2016). 
shamed.' 'Shaming' appeared in English-language books twice as often in 2008 than in 1988 and was a CollinsDictionary.com word of the year in $2015 .{ }^{2}$

Despite our current cultural preoccupation with it, shaming has been neglected in moral philosophy. This might be because of an assumption that shaming, as a kind of negative personal evaluation, is roughly equivalent to blaming, a phenomenon we have already analyzed in depth. Alternatively, philosophers might assume that to shame is simply to produce shame, and shame itself has already received considerable philosophical attention.

My goal in this paper is to offer an overdue definition of shaming. My definition will show that shaming is not the same as blaming, nor is it simply the production of shame. Working from a set of paradigmatic cases of shaming, I argue that shaming can take two forms. The first, agential shaming, is a form of blaming. It consists of blaming an individual for some wrongdoing or flaw by expressing a negative reactive attitude towards her, and inviting an audience to do the same (in cases of private shaming, one invokes an audience rather than actually inviting them). This is the kind of shaming experienced by Monica Lewinsky in the 199os. It is a key way of enforcing social norms.

The second form of shaming, non-agential shaming, is not a form of blaming. Like agential shaming, it involves negatively evaluating a person and inviting an audience to join in this evaluation. Yet the evaluation in question is not a form of blaming, because the shamer is not holding the target morally responsible for anything. Rather, it is a cruder form of public evaluation; non-agential shamers typically express not reactive attitudes, but rather objective attitudes like disgust, and invite others to do the same. People are often non-agentially shamed for having periods, for having certain body shapes, for being 'ugly,' and for being victims of rape. Non-agential shaming thus functions to enforce social standards and values, many of which are oppressive.

Objective attitudes have received less attention in moral philosophy than reactive attitudes, perhaps because of an assumption that we rarely experience or express them. My account of shaming places objective attitudes in the spotlight and demonstrates that they in fact play a significant role in our interpersonal lives.

\section{$1 \quad$ Blaming}

Shaming and blaming appear to be similar, so before theorizing the former, we should remind ourselves of the nature of the latter. Blaming, in short,

2 Google, n.d. "Google Books Ngram Viewer: 'Shaming'.” Accessed September 1 2020. https:// books.google.com/ngrams/graph?content=shaming\&year_start=1988\&year_end=2008. 
is the act of communicatively holding a person morally responsible for something.

Holding a person morally responsible for something is different from judging a person to be morally responsible for something. To judge a person to be morally responsible for something is to judge that her conduct and her relation to that conduct are such that she is liable to praise or blame, i.e. that she is praiseworthy or blameworthy. This is a cognitive appraisal which need not have an affective dimension. Judgments of moral responsibility can be both aretaic and deontic; one can be praiseworthy or blameworthy not just for actions, but also for dispositions, beliefs, and attitudes. Our judgments of moral responsibility are typically guided by what we know about the agent's control over her conduct, and her epistemic relation to it. We usually judge a person to be morally responsible for some wrongdoing if she was in sufficient control of herself and the conduct in question, and possessed the requisite knowledge, beliefs, and intentions. ${ }^{3}$

Holding a person morally responsible, meanwhile, involves not only a judgment of moral responsibility, but also an affective engagement with the target. It involves taking up what Peter Strawson calls a reactive attitude towards her. Reactive attitudes are 'essentially natural human reactions to the good or ill will or indifference of others towards us, displayed in their attitudes and actions. ${ }^{4}$ A reactive attitude is an affective recognition that someone we believe to be a moral agent, i.e. someone we are disposed to regard as capable of moral responsibility and with whom we exchange reasons, has engaged in conduct which displays either goodwill, ill will, or indifference to others.

Reactive attitudes can take many different forms, including gratitude, resentment, indignation, guilt, forgiveness, love, and anger. ${ }^{5}$ It is possible that one could have a reactive attitude but not express it; I can resent someone without expressing my resentment. Yet I will focus specifically on the expression of reactive attitudes, and of negative reactive attitudes in particular.

To blame someone is to communicatively hold them responsible for some wrongdoing or flaw by expressing a negative reactive attitude. The specific reactive attitude we express in blaming depends on who we are blaming and why. If I am blaming a person for showing ill will to me specifically, I likely

3 On the control condition for moral responsibility, see John Martin Fischer and Mark Ravizza, Responsibility and Control: A Theory of Moral Responsibility (Cambridge: Cambridge University Press, 1999). On the epistemic condition, see Philip Robichaud and Jan Willem Wieland, Responsibility: The Epistemic Condition (Oxford: Oxford University Press, 2017).

4 P. F. Strawson, Freedom and Resentment: And Other Essays (London: Routledge, 2008), pp. 10-11.

5 Ibid. 
experience a reactive attitude like resentment. This is for Strawson a 'personal' or 'participant' reactive attitude. ${ }^{6}$ I could express this attitude either directly towards the person who has wronged me, in which case this would be second-personal blaming, or in conversation with someone else, in which case this would be third-personal blaming. ${ }^{7}$

If I am blaming a person for showing ill will or indifference to others, the reactive attitude I express is not resentment, because it is not personal; rather it is a 'vicarious analogue of resentment,' which Strawson thinks is something like indignance or disapprobation. ${ }^{8}$ I feel this reactive attitude on someone else's behalf; I am reacting to the quality of my target's will towards someone else, not to me. Again, this blaming could be second-personal, if I directly confront the person who has wronged others, or third-personal, if I blame her in conversation with someone else.

Sometimes our blaming acts are inappropriate. For example, we blame people for things they are not morally responsible for, or we blame them too severely or not severely enough, or we blame them in the wrong way or at the wrong time. Henceforth I will use 'blaming' to refer to a communicative act made by one person to another which holds a person (who may or may not also be the addressee) morally responsible for something. One does this by expressing a negative reactive attitude. This blaming may or may not be appropriate.

\section{Analyzing Shaming}

I move now from the familiar concept of blaming to the less familiar concept of shaming. ${ }^{9}$ I aim to answer two questions: what exactly is shaming, and how does it relate to blaming?

$6 \quad$ Ibid.

7 I set aside cases of blame in which the object of the blame and/or the addressee of the blame is oneself. These may be possible, but I am interested primarily in the blaming of others, directed at others.

8 Strawson, Freedom and Resentment, p.15.

9 I have found two other definitions of shaming. The first is in Krista Thomason, Naked: The Dark Side of Shame and Moral Life (New York: Oxford University Press, 2018). Thomason argues that shaming involves the 'marshalling of communal attention' and occurs 'when others try to make prominent some feature of the shamed person sometimes for her own self-awareness but mostly for others to see' (p.181). This account is promising but underdeveloped, insofar as it fails to explain how shaming relates to blaming. Paul Billingham and Tom Parr, meanwhile, define public shaming in 'Enforcing Social Norms: The Morality of Public Shaming, European Journal of Philosophy forthcoming (2020). Yet I am interested in shaming simpliciter, which need not be public. 
There are several ways one could go about answering these questions. One would be to look for a definition of shaming in the legal literature on shaming penalties for people who break the law. An example of such a penalty would be forcing drunk drivers to wear signs informing others of their crimes..$^{10}$ However, this literature focuses on a very specific kind of institutional shaming, with a specific shamer - the legal system - and a particular kind of target - a person who has broken the law. I am interested in shaming in general, and so this literature is too specific to use as a starting point.

Alternatively, I could assume that the nature of shaming is parasitic on the nature of shame, and try to deduce a definition of shaming from a definition of shame. I am happy to grant that there is probably some relationship between shaming and shame. Being shamed is often a cause of shame, so we can assume that the act of shaming likely has features which make it well-suited to the production of shame.

However, I resist starting my analysis of shaming with an analysis of shame for several reasons. Firstly, as Julien A. Deonna, Raffaele Rodogno, and Fabrice Teroni have pointed out, 'the process of shaming is not essential to shame.'11 We can feel shame for a variety of reasons. Sometimes shame results from shaming, but sometimes it results from other interactions and experiences. So we may not get far with the observation that shaming is good at producing shame, since many things are good at producing shame.

Secondly, the precise nature of the relationship between shaming and shame is unclear; it cannot be causal since shaming often fails to produce shame. It cannot be necessarily a matter of the shamer's intention, either, since some shamers are not interested in making their targets feel shame. In fact, Deonna et al. go as far as to claim that shaming 'fails to exhibit any privileged connection with shame. ${ }^{\prime 2}$

Thirdly, starting my analysis with a definition of shame would require taking a stance on something about which there is no philosophical consensus. I am happy to grant some uncontroversial claims about shame: that it is negative and that we can feel shame about both things we are morally responsible for and things we are not morally responsible for. Yet I am loathe to assume more

10 For representative legal work, see John Braithwaite, Crime, Shame, and Reintegration (Cambridge: Cambridge University Press, 1989); Dan M. Kahan, 'What Do Alternative Sanctions Mean?' The University of Chicago Law Review 63 (1996), pp. 591-653; Stephen P. Garvey, 'Can Shaming Punishments Educate?' The University of Chicago Law Review 65 (1998), pp. 733-94.

11 Julien Deonna, Raffaele Rodogno, and Fabrice Teroni, In Defense of Shame: The Faces of an Emotion (Oxford: Oxford University Press, 2011), p.158.

12 Ibid. 
than this, given that the other features of shame are contested. For example, some argue that shame involves an audience, real or imagined..$^{13}$ Others argue that shame involves a belief that we have fallen short of our ideals, or a sense that some aspect of our identity has come to define us. ${ }^{14}$ It may be that there are different kinds of shame, and only one of them is typically produced by shaming. Assuming a particular definition of shame risks unnecessarily constraining my analysis, and unnecessarily alienating proponents of alternative definitions.

My analysis of shaming will instead proceed as follows. I will attempt to unpack what 'shaming' means for ordinary language speakers. I will do this by examining six paradigm cases of shaming, all of which are chosen because they have been widely described as 'shaming' in the media, academia, and beyond. I will attempt to identify common features of these examples, focusing in particular on the attitudes the shamers express, the objects of their shaming, and how these compare to the typical attitudes of blamers and the typical objects of blaming.

Here are the six cases:

Hester: Hester, the main character in Nathaniel Hawthorne's The Scarlet Letter, is estranged from her husband and has a child with another man..$^{15}$ She is made to stand on a public platform for several hours, carrying her baby and wearing an embroidered letter 'A,' representing her status as an 'adulteress.'

Shorn Women: After WW2, over 20,0oo French women accused of collaboration with the Nazis were subjected to forcible public head shavings. ${ }^{16}$

13 For arguments that shame involves an audience, see John Deigh, 'Shame and Self-Esteem: A Critique,' Ethics 93 (1983), pp. 225-45; Allan Gibbard, Wise Choices, Apt Feelings: A Theory of Normative Judgement (Oxford: Oxford: Clarendon Press, 1990); Bernard Williams, Shame and Necessity (Berkeley: University of California Press, 1992); Heidi Maibom, 'The Descent of Shame,' Philosophy and Phenomenological Research 8o (2010), pp. 566-94. For arguments that an audience is inessential, see Gabriele Taylor, Pride, Shame, and Guilt: Emotions of Self-Assessment (Oxford: Oxford University Press, 1985); R. Jay Wallace, Responsibility and the Moral Sentiments (Cambridge: Harvard University Press, 1994); Michelle Mason, 'On Shamelessness,' Philosophical Papers 39 (2010), pp. 401-25; Deonna et al, In Defense of Shame; Thomason, Naked. Some argue that shaming involves an audience, but that audience can be imagined. For example, Cheshire Calhoun argues that shame involves a 'representative other' - 'An Apology for Moral Shame,' Journal of Political Philosophy 12 (2004), pp. 127-146. See Rawls, A Theory of Justice, p.388 and Thomason, Naked respectively.

15 Nathaniel Hawthorne, The Scarlet Letter (London: Vintage Classic, 2008).

16 Ann Mah, 'This Picture Tells a Tragic Story of What Happened to Women After D-Day' Time, June 6, 2018, http://time.com/5303229/women-after-d-day/. 
Some of these women had collaborated (though often out of desperate need to provide for their families). Yet some had been raped by Nazi soldiers and/or coerced by them into offering lodgings.

Monica: Monica, a White House intern in the 199os, had a sexual relationship with the married President, Bill Clinton. She observes that when news of this relationship broke, she 'went from being a completely private figure to a publicly humiliated one worldwide,' and was branded a 'tramp,' 'tart,' and 'slut' in the media. ${ }^{17}$ She calls herself the 'patient zero' of internet shaming. ${ }^{18}$

Justine: Justine, a P R executive, tweeted the following joke: 'Going to Africa. Hope I don't get AIDS. Just kidding. I'm white!' Over 100,00o tweets then condemned Justine and called for her to lose her job, many using the hashtag \#HasJustineLandedYet and some threatening abuse and murder. Justine was fired and forced to move house after the shamers shared her address. ${ }^{19}$

Stacey: Stacey is a reality TV star. The Sun newspaper posted a photo of her in a bikini at the beach, with the caption 'Top flop: X Factor singer Stacey gets that sinking feeling,' referring to her breasts. ${ }^{20}$ This was widely described as 'body-shaming. ${ }^{21}$ Women are often body-shamed for their weight; the shape and size of their breasts, stomachs, and buttocks; their body hair; and their skin. Men experience body-shaming too; Stormy Daniels publicly apologized in 2018 for body-shaming Donald Trump after making comments about his genitalia. ${ }^{22}$

17 Monica Lewinsky, 'The Shame Sticks to You like Tar,' The Guardian, April 16, 2016, https://www.theguardian.com/technology/2016/apr/16/monica-lewinsky-shamesticks-like-tar-jon-ronson. Monica Lewinsky, 'The Price of Shame,' TED, 2015, https://www.ted.com/talks/ monica_lewinsky_the_price_of_shame.

19 Justine's story is discussed in detail in Ronson, So You've Been Publicly Shamed.

20 Kim Carr, 'X Factor to Sun Factor', The Sun, August 16, 2016.

21 Rachel Moss, 'Stacey Solomon Hits Back At Body-Shaming Article In The Sun,' HuffPost UK, August 22, 2016, https://www.huffingtonpost.co.uk/entry/stacey-solomon-hits-back-at-bodyshaming-article-in-the-sun_uk_57baaeffe4bo42aee74c5115.

22 David Barden, 'Stormy Daniels Regrets “Body Shaming” Trump', HuffPost UK, August 10, 2018, https://www.huffingtonpost.co.uk/entry/stormy-daniels-6o-minutes-australia_n_5bbagd 3oe 4bo28eifezea8e5?ri18n=true. 
Carrie: Carrie, a character in the eponymous novel by Stephen King, gets her first period at school whilst showering after a sports lesson. Her fellow students torment her verbally and physically; 'The laughter, disgusted, contemptuous, horrified, seemed to rise and bloom into something jagged and ugly, and the girls were bombarding her with tampons and sanitary napkins. ${ }^{23}$ This scene is often used as an example of 'period shaming,' something half of American women and one in three British women report experiencing. ${ }^{24}$

One might wonder whether these examples could be alternatively or additionally classified as acts of embarrassing, humiliating, or mocking. These phenomena can certainly overlap, but there are some subtle differences between them. To embarrass someone is to cause her to feel embarrassment. This is why a sentence like 'She embarrassed him, but he was not embarrassed' does not make sense. While 'to embarrass' is a causal verb, 'to shame' is not; we can and do say things like 'She was shamed, but she was not ashamed.' One can shame a person without causing her shame.

Humiliation, like embarrassment, also seems to be a causal act; it is much easier to imagine shaming someone without causing them to feel shame than it is to imagine humiliating someone without causing them to feel humiliated. Relatedly, it seems easier to humiliate a person unintentionally. We sometimes speak of 'humiliating' defeats in sports or elections; these can occur even when no particular actors sought to 'humiliate' the loser. In contrast, though we might call a defeat 'shameful,' i.e. worthy of shame, we do not typically speak of 'shaming' defeats.

Mockery, meanwhile, admits of more benevolence than shaming. Though mockery can be very cruel, one can also mock someone light-heartedly and gently. In contrast, shaming is rarely light-hearted or benevolent. Mockery, more so than shaming, also has an element of humor. To mock someone is to 'make fun' of them, which explains why those who engage in it often do so with a smile. The same is not true of shaming. Additionally, person A can mock person B in conversation with person C without B ever knowing, whereas the targets of shaming are usually involved in the act of

23 Stephen King, Carrie (London: Hodder \& Stoughton, 1974), p.13.

24 Valerie Siebert, 'Nearly Half of Women Have Experienced "Period Shaming", New York Post, January 3, 2018, https://nypost.com/2018/o1/o3/nearly-half-of-womenhave-experienced-period-shaming/; Action Aid, 'More than One in Three UK Women Face Period Stigma,' May 25, 2018, https://www.actionaid.org.uk/latest-news/ more-than-one-in-three-uk-women-face-period-stigma. 
shaming. I could secretly mock you, but it is less clear that I could secretly shame you.

None of these distinctions are particularly stark. In what follows I concentrate on shaming because it has received the most public attention in recent years. I leave the question of exactly how this phenomenon relates to embarrassment, humiliation, and mockery to future work.

The six acts of shaming under consideration have several features in common. Firstly, they all involve the communication of a negative evaluation of a person. In some cases, the shamer clearly expresses a negative reactive attitude towards the target and is therefore holding that target responsible. This makes some of these cases look a lot like blaming - I return to this fact in $\S 4$.

Secondly, in all six cases the shamers deliberately provide a third party (henceforth 'the audience') with information about the target and her alleged transgression or flaw, in order to encourage that audience to also engage in negative evaluation of the target. Hester is made to wear the scarlet letter so that everyone can learn of her transgression, and she is exhibited on a raised platform so that a large assembled mob can see her. The shorn women were shaved in town squares so people could watch. They often had swastikas painted on their faces, and after the shavings they were paraded through the streets to maximize exposure. Monica's shamers used catchy newspaper headlines to maximize their readership. Justine's shamers used the hashtag\#HasJustineLandedYet to inform followers about Justine and to co-operate with other shamers. The Sun released a zoomed-in photo of Stacey's breasts in a national newspaper. Carrie's shamers co-ordinate their shaming by pointing at Carrie and throwing things at her, while chanting phrases in unison.

All of these shaming acts are what speech act theorists call 'ostensive acts'; they involve ostending, or pointing, towards an entity (in this case a person) and calling upon other agents to observe, acknowledge, and respond to that entity. These shaming acts hold up the target and her failings for public view and invite others to recognize them. Shaming a person is not equivalent to saying, 'That person has a flaw,' or 'You have a flaw'; instead, it is equivalent to saying, 'Look everyone, recognize this person and her flaw!' The recognition involved in shaming is normative; the shamer 
takes herself to have identified some 'bad' feature of the target and invites others to recognize it with her. ${ }^{25}$

Thirdly, the shamers all involve the targets of their shaming in the act of shaming. For this reason, shaming often blurs the line between the second-personal and the third-personal. Sometimes, shaming is addressed to the person being shamed, but in the knowledge that others are looking on. For example, some of Carrie's shamers address her directly, but with the intention that others hear what they are saying. The audience is not, to use Erving Goffman's terminology, a mere 'bystander' to the shaming, i.e. an unintended hearer who could become an inadvertent 'overhearer' or a deliberate 'eavesdropper.'26 Rather, the audience is a 'ratified' hearer; they are an intended participant in the exchange. Even if the speech is not directly addressed to them, the speaker intends that they hear it.

Other times, shaming is addressed to the audience, but in the knowledge that the person being shamed is looking on, in which case the shamer herself is a non-addressed but nonetheless ratified hearer. For example, those using \#HasJustineLandedYet were technically addressing each other, not Justine. Yet they spoke to each other in the knowledge and with the intention that Justine would eventually read their tweets. Thus, even if a shamer does not address the person being shamed, she wants her to know what is happening. In either case, shaming involves a set of ratified participants, comprising the target of the shaming as well as other hearers.

In contrast, a blamer need not involve an audience who is not her target in her act of blaming. In both second-personal and third-personal blaming, it suffices that the blamer has just one hearer; the person she addresses. She need not call upon anyone else to join the interaction, and she need not engage in any kind of ostensive act. She also need not have an interest in others coming to share her attitudes. In cases of third-personal blame, there may be an element of reporting; she may need to explain to her interlocutor why she is

25 The audience need not actually take up the invitation for the act to qualify as shaming; it suffices that the shamer merely invites them (or at least invokes their judgment - more on that shortly). This is borne out in the fact that we often shame people for shaming others, even if their shaming acts had no purchase on their intended audiences. For example, in 2019 a teacher in North Carolina uploaded a video to social media complaining about a disabled student (who was visible in the video). This teacher was widely criticized for 'shaming' her student, even though no one took up her invitation to join in her criticism of the student. See Elsa Gillis, 'Mooresville Teacher Resigns after Video Shows Her Shaming Student in Wheelchair,' WSOCTV, August 30, 2019. https://www.wsoctv.com/news/local/mooresvilleteacher-resigns-after-video-shows-her-shaming-student-in-wheelchair/980896048/.

Erving Goffman, Forms of Talk (Oxford: Basil Blackwell, 1981), p.132. 
blaming someone, but she need not call upon the hearer to join in the blaming. The target of a blaming act need not be involved in the act, either. She is necessarily involved in second-person blaming, as she is addressed directly by the blamer. Yet in cases of third-person blaming, she need not be involved at all. A could blame B in conversation with $C$ without $B$ ever knowing; indeed, sometimes A may desire that B never know about it.

That shaming at least often involves an audience could explain why interest in shaming has increased since the 199os. This is the same decade the masses gained access to the Internet, which has enabled us to communicate with thousands of people quickly, easily, and freely. We have always been able to engage in shaming, but the advent of the Internet has made (at least certain forms of) shaming much easier, by giving us immediate access to massive audiences.

That shaming involves an audience could also explain why shaming typically produces shame, at least according to some definitions of shame. Studies show firstly that shame is often experienced in the presence of others. ${ }^{27}$ Secondly, it is more intense the greater the public exposure involved. ${ }^{28}$ Thirdly, it is disproportionately triggered by external factors, relative to other emotions. ${ }^{29}$ If, as these studies suggest, shame is a social emotion, we should expect that a process which typically produces shame - the act of shaming - is also social in some way.

\subsection{Private Shaming}

It is tempting, then, to conclude that shaming necessarily involves an audience. If this is true, then private shaming is impossible. Yet this is counter-intuitive; it certainly seems possible for a mother to privately period-shame her daughter, or for a man to privately slut-shame his girlfriend. Indeed, the fact that we use the phrase 'public shaming' suggests that shaming is not necessarily public.

We could try to argue away the potential counterexamples of private shaming. Imagine that a mother tells her daughter that her periods are disgusting, and that she should hide all evidence of them. This interaction may well involve shame in some way, but we should resist the temptation to classify all acts that involve shame as shaming acts. Perhaps an act like this is not shaming, but rather what Krista Thomason calls an 'invitation to shame.' She defines this as an intentional

27 June Price Tangney and Ronda L. Dearing, Shame and Guilt (New York: Guilford Press, 2002).

28 Richard H. Smith, J. Matthew Webster, W. Gerrod Parrott, and Heidi L. Eyre, 'The Role of Public Exposure in Moral and Nonmoral Shame and Guilt,' Journal of Personality and Social Psychology 83 (2002), pp. 138-59.

29 H.G Wallbott and K.R. Scherer, 'Cultural Determinants in Experiencing Shame and Guilt', in J.P. Tangney and K.W. Fischer (eds.), Self-Conscious Emotions: The Psychology of Shame, Guilt, Embarrassment and Pride (New York: Guilford Press, 1995), pp. 465-87. 
action, 'usually done face-to-face or at least on a small scale,' which prompts targets to re-think their actions or behaviors. Such invitations 'unseat or shake our own view of ourselves.' In contrast, Thomason thinks that a shaming act has a public dimension: 'it holds up flaws or misdeeds for public view.'30

While Thomason is right that shaming someone and encouraging her to feel shame are distinct, this distinction alone does not eliminate worries about private shaming. Even if one accepts that not all actions involving shame are shaming acts, one may nonetheless maintain that a mother can privately period-shame her daughter, in addition to inviting her to feel shame. Moreover, to deny that shaming can occur in private would be to dismiss people's actual usage and understanding of the concept of shaming.

I propose instead that we maintain that an audience plays a role in shaming, but we modify our understanding of what an audience is and what role they must play. Shaming acts need not involve an actual audience, i.e. they need not actually invite them to pass judgment, but they must invoke the judgment of an audience, real or imagined. This meshes well with accounts of shame as an emotion that requires the ashamed person to consider the judgment of an other - the judgment and the other can be real, or they can be merely hypothetical or imagined. ${ }^{31}$ Shaming, similarly, invokes the judgment of the other, and perhaps that other need not be real or present.

When a mother privately period-shames her daughter, she likely tells her that periods should be hidden from others; she thereby invokes the hypothetical negative evaluation of the other (where that evaluation could take the form of a reactive attitude, or some other kind of evaluative attitude). The girl learns that her community would be disgusted if they encountered evidence of her periods. Similarly, when a man slut-shames his wife in private, he likely invokes the hypothetical judgment of the community, and tells her that in society's eyes, she is 'lesser' on account of her sexual experiences. In cases of shaming with a real audience, the shamer tells the target that she recognizes her flaw, and she calls on others to also recognize it. In cases of shaming with a hypothetical audience, the shamer tells the target that she recognizes her flaw, and she calls on the target to imagine what other people would think of the flaw.

Thus we can have public and non-public shaming; public shaming involves a real audience, while non-public shaming involves a hypothetical audience. Both forms of shaming are social, since they invoke the judgment of another, even if that other is not physically present. This distinguishes them from ordinary blaming; when I blame you for letting me down, I need not invoke the

30 Thomason, Naked, pp. 179-180.

$31 \quad$ See fn. 13 . 
hypothetical negative evaluation of anyone but me. If there were, and had only ever been, two people on Earth, and they had no conception of other agents, it seems possible that one could blame the other. Whether they could shame each other is more doubtful.

\section{Shaming and Responsibility}

The six cases of shaming under consideration are all acts of negative personal evaluation involving audiences. Yet there is also disunity among them. They can be separated into two groups; call the shaming typified by the first group agential shaming, and the shaming typified by the second group non-agential shaming.

In the agential shaming group are Hester, Shorn Women, Monica, and Justine. All four are examples of blaming, because the shamers all communicatively hold their targets morally responsible for some wrongdoing (adultery, treachery, 'promiscuity, and racism, respectively) by expressing negative reactive attitudes. Hence agential shaming is just a social (often public) form of blaming. Not all blaming counts as agential shaming, but all agential shaming counts as blaming. Agential shaming involves blaming a target and calling on others to blame her too.

In the non-agential shaming group are Stacey and Carrie, and some but not all of the shorn women - those who were shamed not for treachery but rather for being victims of rape by the Nazis. These cases are not acts of holding people morally responsible. Stacey is shamed for something her shamers know she cannot be responsible for; the shape of her breasts. The same is true of Carrie's period-shaming; she cannot help menstruating, and the girls shaming her know this (especially since most of them menstruate, too). Some cases of Shorn Women involved agential shaming, insofar as the victims were believed to be traitors, but some of the victims were known to be victims of rape by Nazi soldiers. The latter women were shamed for something the shamers knew they were not responsible for. Because these are not acts of holding responsible, they cannot be acts of blaming. ${ }^{32}$

32 The words 'shameful' and 'shameless' are more pertinent to agential shaming than to nonagential shaming. We typically call a person 'shameful' if she has done something very wrong. It is often a way of expressing a negative reactive attitude towards a person, holding her responsible for some grave wrongdoing. We typically call a person 'shameless,' meanwhile, if she has done something wrong, but failed to be ashamed of it. Being shameless can itself be shameful; some think that an absence of shame is something for which one should be ashamed. We can conceive of any of Hester, the Shorn Women, Monica, or Justine being described as either shameful or shameless. It is harder to imagine Stacey or Carrie being described as 'shameful' or 'shameless'; these words are means of holding someone responsible, and Stacey and Carrie cannot be and are not held responsible for their bodies. 
Before I explore the nature of these cases further, I will pre-empt two objections. The first is that Stacey, Carrie, and this subset of shorn women were ultimately being held responsible for something, just not any of the characteristics I list. Perhaps Stacey was shamed not for the shape of her body, but rather for daring to wear an outfit that revealed her body; maybe in doing so, she demonstrated that she was not sufficiently ashamed of her body, or she inflicted the 'harm' of seeing her body upon others. Alternatively, The Sun might be shaming Stacey for her failure to 'rectify' her body, i.e. her failure to have surgery to make her body better resemble the 'ideal' woman's body. In either case, there could be an allegation of moral wrongdoing after all.

However, though we might be able to explain away Stacey's body-shaming in this way, we cannot explain away all body-shaming in this way. Often people are body-shamed when the shamers know quite well that the target has no moral responsibility for the appearance of her body, and when the target has done nothing to provoke the thought that she is not sufficiently ashamed or that she is acting 'above her station.' Consider the ways in which women are shamed for being tall, broad, or 'manly.' Shamers know that women are not responsible for these characteristics and cannot change them. Genitalia shaming offers another example of body-shaming where the shamer cannot be holding the target responsible for anything; when Stormy Daniels shamed Trump for his genitalia, she knew he was not responsible for his body, and she was not accusing him of inappropriately drawing attention to it. She was shaming him simply for possessing a particular characteristic.

One might wager that Carrie, meanwhile, is being shamed not for menstruating, but rather for her failure to hide her menstruation. After all, in the scene in question, the girls shout, 'Plug it up!' and 'Clean yourself up!' It is conceivable that one could agentially shame a girl for a period stain on the grounds that she was wrongfully negligent, but since this was Carrie's first period, she cannot have been expected to prevent others seeing her blood by wearing a tampon. The shamers knew that it was her first period, as they are described as finding her naivety amusing. Thus, they can only be shaming her for the very fact of her menstruation (or perhaps her naivety, but this is not something that she can be held responsible for, either).

As for the rape victim example, I acknowledge that rape victims are frequently held morally responsible for their assaults, i.e. they are blamed, even though they in fact bear no moral responsibility for what happened. Victims are often accused of 'leading on' the perpetrators or acting recklessly in ways that made them morally responsible for what happened 
next. ${ }^{33}$ Yet victim-blaming and victim-shaming can come apart. Sometimes the shamer believes that the victim was not responsible, and does not pretend otherwise, but shames her anyway. Shaming of this kind is especially prevalent among cultures which value honor and purity. Shamers might think that the rape victim has acquired a characteristic that dishonors or disvalues her, making her 'damaged goods.' It is her mere possession of the characteristic that makes her worthy of shaming, regardless of how she acquired it or what she could do about it.

Implicit in this kind of thinking is an idea of contamination, a concept I will explore in more detail shortly. As a tribal leader (and advocate of honor killings) in Jordan puts it, 'a woman is like an olive tree. When its branch catches a woodworm, it has to be chopped off so that society stays clean and pure. ${ }^{34}$ It is not the branch's 'fault' that it gets woodworm, but it must still be condemned and eliminated. Likewise the thought is that though the victim is not responsible for her rape, she is still unclean and impure as a result. Similarly, Tamler Sommers observes that rape victims murdered in honor killings are often viewed as possessing 'some kind of terminal and contagious disease.'35

The second objection I pre-empt is the claim that Stacey, Carrie, and some of the shorn women are being held morally responsible, and thus blamed, for the characteristics I originally identified, but the notion of responsibility invoked in these cases does not have the same epistemic or control conditions we are used to.

Sommers, in an exploration of honor killings, takes seriously the possibility that understandings of moral responsibility vary across cultures, and suggests that this can help us make sense of the phenomenon of killing a family member because she is a victim of rape:

Imagine that the cultures supporting this behaviour do not regard intention or control as a necessary condition for moral responsibility. If that is the case, it becomes almost irrelevant that the victim did not choose, or

33 Psychologists argue that we blame rape victims because we are disposed to interpret the world as just. We want to believe that good is rewarded and evil punished. Because rape is so disquieting, we reframe it as just, telling ourselves that it was not spontaneous evil, but rather something deserved. See Leo Montada and M.J. Lerner, Responses to Victimizations and Belief in a Just World (New York: Plenum Press, 1998).

34 Quoted in Clare Murphy, 'Jordan's Dilemma over "Honour Killings", $B B C$, September 10, 2003. http://news.bbc.co.uk/1/hi/world/middle_east/3094736.stm.

35 Tamler Sommers, Relative Justice: Cultural Diversity, Free Will, and Moral Responsibility (Princeton: Princeton University Press, 2012), p.52. 
intend, to have extramarital sex. All that matters is that the act occurred. The idea that it is unjust to punish someone for unintended acts would not resonate as much to members of these cultures. ${ }^{36}$

Elsewhere, he observes that:

Honour cultures have a diminished notion of deservingness, and what appears to be a vastly stripped down control condition, which institutionalised cultures consider to be the very essence of moral responsibility. ${ }^{37}$

Sommers notes that this way of thinking was common in Greek cultures, citing the example of Agamemnon being held morally responsible by those around him for a murder he was forced to carry out. He observes that in the Greek honour culture, one could be responsible and justly punished for fated, constrained, or manipulated actions, whether one identified with the action or not.'38

It is certainly important to remain open-minded about differing conceptions of moral responsibility. Yet all of the examples of non-agential shaming I am considering occurred in Western cultures, and as Sommers himself asks, 'what principle could be more fundamental to Western notions of moral responsibility than the claim that only the culpable, only those who had control over their actions, deserve blame and punishment?'39 These shamers do not possess an alien concept of moral responsibility. They likely possess a very familiar concept of moral responsibility, but are simply not utilizing it when they engage in non-agential shaming.

Thus, the shamers involved in Stacey, Carrie, and some of the Shorn Women cases are not holding their targets morally responsible for misdeeds like negligence or recklessness, nor are they incorrectly ascribing moral responsibility where there is none (though I grant that this can happen, especially when shamers believe rape myths), nor are they invoking a non-standard notion of moral responsibility. Rather, they are not holding their targets morally responsible at all.

36 Ibid.

37 Tamler Sommers, 'The Two Faces of Revenge: Moral Responsibility and the Culture of Honor,' Biology and Philosophy 24 (2009), pp. 35-5o, p.48

38 Sommers, Relative Justice, p.52.

39 Sommers, 'The Two Faces of Revenge,' p.48. 


\section{$5 \quad$ Shaming and Objective Attitudes}

That some forms of shaming do not involve holding the target morally responsible is an interesting result in its own right. However, I will now consider what non-agential shaming might involve, if it is not the act of holding responsible, i.e., I will move from showing what non-agential shaming is not to considering what it might be.

\subsection{Objective Attitudes}

Given that non-agential shamers do not hold their targets responsible, they cannot be expressing Strawsonian reactive attitudes, qua natural human reactions to the wills of others. The attitudes they are expressing might therefore take the form of an objective attitude instead. Strawson says of the latter:

To adopt the objective attitude to another human being is to see him, perhaps, as an object of social policy; as a subject for what, in a wide range of sense, might be called treatment; as something certainly to be taken account, perhaps precautionary account, of; to be managed or handled or cured or trained; perhaps simply to be avoided [...] The objective attitude may be emotionally toned in many ways, but not in all ways; it may include repulsion or fear, it may include pity or even love, though not all kinds of love. ${ }^{40}$

Strawson lists several circumstances in which we might take up an objective attitude: when we encounter someone who is 'warped or deranged, neurotic or just a child'; when we seek refuge from the 'strains of involvement'; when we require an 'aid to policy'; and when we want to examine human behavior 'out of intellectual curiosity.41 Taking up the objective attitude is often a barrier to meaningful interpersonal interaction. It can involve seeing others as 'posing problems simply of intellectual understanding, management, treatment, and control. ${ }^{12}$ Strawson attributes this attitude to the 'one-eyed' utilitarian, who sees people at worst as obstacles or pawns and at best as bearers of utility, and not as agents who demand inter-personal regard. When this utilitarian makes evaluative judgments of other people, these judgments are not responses to others' humanity, but rather methods of social control. ${ }^{43}$

\footnotetext{
40 Strawson, Freedom and Resentment, pp. 9-10.

41 Ibid.

42 Strawson, Freedom and Resentment, p.18.

43 Strawson, Freedom and Resentment, p.25
} 
Philosophers often speak of 'the' objective attitude as if it were relatively impassive, and as if it takes only one form. Neither of these is the case. Strawson makes clear that the objective attitude can be 'emotionally toned,' and it can take on many forms, with both positive and negative valence. He suggests that even love can sometimes be a form of objective attitude; after all, we can love a person for traits for which we know she is not responsible. Negative objective attitudes, meanwhile, can take the form of hatred, disgust, contempt, fear, annoyance, disdain, and pity. We often take up negative objective attitudes when we see people as irritants, nuisances, and obstacles, i.e. when they are displeasing in ways which have nothing to do with their goodwill, ill will or indifference towards us and others. Hate speakers often seem to take up objective attitudes towards minority groups, viewing and characterizing them as vermin or pests which must be controlled or eliminated. ${ }^{44}$

Strawson suggests that usually we can only take up objective attitudes temporarily; 'being human, we cannot, in the normal case, do this for long. ${ }^{45} \mathrm{We}$ might question his optimism here; after all, throughout history many social groups have been regarded by others as entities 'to be managed or handled or cured or trained' for long periods of time; this attitude has played a key role in practices like slavery and genocide, for example. Yet Strawson is right that it is possible to take up an objective attitude towards a person one moment, and then resume the 'participant attitude,' i.e. the general disposition to regard the person as an agent and react to her as such, the next.

When we engage in non-agential shaming, I suggest, we express a localized objective attitude. We focus on one particular feature of a person which displeases us not because it manifests her ill will but simply because it presents some kind of obstacle to us; it might disgust us, scare us, or frustrate our desires. We hold up this flaw to others and invite them to share in our distaste, i.e. to express the same negative objective attitude towards the target. We need not do this all the time; we could non-agentially shame the agent one moment, and then return to regarding her as a moral agent the next. Or, our objective attitude might be more totalizing; that the non-agential shaming of rape

44 The boundaries between hate speech and non-agential shaming are blurry, but there are some differences. For example, non-agential shaming is generally more localized. It also need not invoke any recognized demographic category; I can non-agentially shame a person for something very specific, like a scar. Hate speech, meanwhile, targets people for their membership of recognized demographic groups. Additionally, unlike non-agential shaming, hate speech does not necessarily involve an audience. The hate speaker need not involve another appraiser, either by inviting them to join in or alluding to their potential negative appraisal.

45 Strawson, Freedom and Resentment, p.10. 
victims often leads to honor killings indicates that these shamers sometimes decide that the target has entirely ceased to be worthy of any moral respect.

\subsection{Disgust}

My claim that non-agential shaming involves expressing an objective attitude could be made more persuasive if I also identified a particular form of objective attitude expressed in the cases under consideration. I propose that in many of these cases, the shamers express the objective attitude of disgust. William Miller defines disgust as 'a strong sense of aversion to something perceived as dangerous because of its powers to contaminate, infect, or pollute by proximity, contact or ingestion. ${ }^{46}$ Paul Rozin et al. have developed a four-part taxonomy of disgust. Core disgust is elicited by physical objects like food, animals, and bodily fluids; animal-nature disgust is elicited by things that remind us that we are mortal animals, like corpses and sex; agential disgust is elicited by strangers and people who are different from us; and moral disgust is elicited by perceived moral violations. ${ }^{47}$ I set aside cases of moral disgust, as this is likely a form of reactive attitude, which would be involved in agential shaming. The other forms of disgust, in contrast, are likely to be involved in non-agential shaming.

That non-agential shaming can involve expressions of disgust explains why such shaming often focuses on bodily characteristics, and women's bodily characteristics in particular. Stacey, Carrie, and the raped shorn women are all shamed for some feature of their bodies, and disgust is often associated with physicality. Miller writes, for example, that disgust operates 'in a kind of miasmic gloom, in the realm of horror, in regions of dark unbelievability, and never too far away from the body's and, by extension, the self's interiors. ${ }^{48}$ Women have long been regarded as more corporeal or 'bodily' than men, and thus their bodies more frequently elicit disgust; the proliferation of menstruation taboos around the world make this plain, as do (typically Western) taboos surrounding public breastfeeding.

All three examples of non-agential shaming involve the evaluation of a bodily property historically considered disgusting. ${ }^{49}$ Stacey elicits disgust because of how her breasts look after having had two children; her breasts are evidence

46 William Ian Miller, The Anatomy of Disgust (Cambridge: Harvard University Press, 1997), p.2.

47 P. Rozin, J. Haidt, and C. McCauley, 'Disgust,' in M. Lewis, J.M. Haviland-Jones, and L.F. Barrett (eds.), Handbook of Emotions (New York: Guilford Press, 2008), pp. 757-76.

48 Miller, The Anatomy of Disgust, p.36.

49 I do not mean to imply that to become a victim of rape is to acquire a new bodily feature. Rather, those who shame rape victims act $a$ if rape victims acquire such a feature. 
of her reproductive function and thus likely elicit 'animal-nature disgust' because they remind the shamers of her animality and mortality. Breasts are typically the most sexualized part of a woman's body, but they are only seen as attractive if they meet strict social standards and are separated from their reproductive function. Stacey is shamed because her body fails to live up to these standards.

Menstruation, for which Carrie is shamed, has historically been considered particularly disgusting. Miller describes menstrual blood as a 'universal disgust substance' and Elizabeth Grosz writes that 'women's menstrual flow is regarded not only with shame and embarrassment but with disgust and the powers of contaminating. ${ }^{50}$

Women who have been raped also elicit disgust. Sometimes this is because of valorizations of virginity, which lead many to believe that a previously 'virginal' woman who is raped becomes ruined, desecrated, or impure in some way. This is borne out in the analogies used to teach young women about abstinence; a woman who has sex before marriage and/or with more than one person is likened to a stick of gum that has been chewed by lots of different people, or a plaster placed on many different people's skin. ${ }^{51}$ Sexual contact with a man is thought to sully a woman; Miller writes of beliefs in the 'defiling power of male sexual contact' and the 'general rule in Western folk beliefs [that] the vagina is more contaminated by ejaculant than the penis is by having penetrated to ejaculate. ${ }^{52}$ Sometimes rape victims elicit disgust because they are reminders of the vulnerability and mortality of human bodies, and of the fact that our bodily integrity can be compromised.

Thus, it is plausible that in all three cases of non-agential shaming, the shamer expresses an emotionally toned objective attitude which takes the form of disgust. I am not claiming that disgust is always the objective attitude involved in non-agential shaming. Contempt is another plausible candidate. However, that disgust plausibly plays a key role in these acts of shaming bolsters the thought that shaming involves the expression of some kind of objective attitude.

50 Miller, The Anatomy of Disgust, p.15; Elizabeth Grosz, Volatile Bodies: Toward a Corporeal Feminism (Bloomington: Indiana University Press, 1994), p.2o6.

$51 \quad$ Jill Filipovic, "Purity" Culture: Bad for Women, Worse for Survivors of Sexual Assault,' The Guardian, May 9, 2013, https://www.theguardian.com/commentisfree/2013/may/o9/ elizabeth-smart-purity-culture-shames-survivors-sexual-assault. 
Agential shaming and non-agential shaming have some features in common, but they are also very different. Agential shaming involves expressing a negative reactive attitude towards a person and inviting others to join in. Nonagential shaming involves expressing a negative objective attitude towards a person and inviting others to join in. Could these practices serve similar social functions?

There are some functions which only agential shaming, and not non-agential shaming, could serve. For example, agential shaming could have a sanctioning function; the shamer punishes her target for her wrongdoing with the weight of both the shamer's own reproach and the (real or imagined) reproach of the masses. Thus, agential shaming might be an attempt to harness the power of the audience to augment the sanctioning function of ordinary second-personal blaming. Agential shaming could also have a deterrent function; by publicly punishing the target, the shamer warns the audience not to act as the target acted (at least in cases where the audience is real). ${ }^{53}$

In contrast, non-agential shaming could not have a sanctioning function. It is certainly a form of adverse treatment, but the target of such shaming is not seen to 'deserve' sanctioning or punishment. Nor could it have a deterrent function, because the kinds of things one is non-agentially shamed for are typically not under one's control. A person watching a peer being shamed for being disabled will not think 'I had better avoid being disabled.'

The two forms of shaming seem to have at least two functions in common, however. Firstly, in cases where there is a real audience involved, both can function to warn the audience about the target. This is particularly pertinent in cases of non-agential shaming involving disgust. Disgust is often regarded as a way we recognize contaminating entities. Recall Miller's claim that to be disgusted by something is to consider it dangerous because of 'its powers to contaminate, infect, or pollute by proximity, contact or ingestion. ${ }^{54}$ This contamination need not be physical - it can also take on spiritual and psychological forms. Martha Nussbaum notes our tendency to assume that we can be

53 Agential shaming's deterrent function was put to use in 'Corona-shaming.' As social distancing measures were enforced globally during the Covid-19 crisis, many encouraged the shaming (using this word specifically) of those who did not social distance. The goal of this shaming was not so much to punish the rulebreakers but rather to make an example of them, thereby discouraging others from breaking the rules. See Jennifer Weiner, 'The Seductive Appeal of Pandemic Shaming,' The New York Times, April 14, 2020, https://www. nytimes.com/2020/04/14/opinion/coronavirus-shaming.html.

Miller, The Anatomy of Disgust, p.2. 
contaminated just by being around disgusting entities; somehow proximity to animal secretions can make us more animal-like, and proximity to the mortal and decaying can make us mortal and decaying. ${ }^{55}$ When one encounters a contaminant, one exposes it and calls attention to it in the hope that others can avoid it. This might be what non-agential shamers are doing: calling on others to recognize the target's contamination. This might also be a function of agential shaming; targets who have transgressed might be seen as morally disgusting, and therefore morally contaminating and to be avoided.

Secondly, both forms of shaming can function to reinforce social meanings. Agential shaming reinforces society's commitment to social and moral norms, and non-agential shaming reinforces society's commitment to social standards. Consider agential shaming first. When we engage in this practice, we typically want to make the target and the audience recognize that the target has done wrong. Agential shaming is thus an effective vehicle for reinforcing norms; the shamer calls on society to recognize the norm the target has violated, and in turn the weight of the majority's condemnation will make the target realize her wrongdoing in a way a single person pointing out that wrongdoing might not. ${ }^{56}$

This idea has motivated the use of legal shaming penalties. Thom Brooks, discussing such penalties, argues that shaming can sometimes be the only way to make a person realize that they committed a wrongdoing. ${ }^{57} \mathrm{He}$ discusses a case in which a person was publicly shamed for stealing mail; the court judged that shaming the defendant was necessary to facilitate a 'wake-up call,' i.e. to make him realize the gravity of what he had done (United States $v$. Gementera, 379 F.3d 596, 604 (9th Cir. 2004)). Agential shaming, for both the shamer, the audience, and the target, can be a way of reinforcing a commitment to a social norm; everyone comes together to confirm that what the target did was wrong.

Non-agential shaming might, similarly, remind or inform the target and the audience that a trait the target has is bad, or disgusting. ${ }^{58}$ Instead of enforcing a social norm, it enforces a social standard. This distinction between norms and

55 Martha Nussbaum, Hiding from Humanity: Disgust, Shame, and the Law (Princeton: Princeton University Press, 2004), p.89.

$5^{6}$ In some cases, the shamers only care about the audience's adherence to the norm, and thus may agentially shame those known to be innocent; in these cases, the victim's suffering is mere collateral damage wrought in service of enforcing a social norm. This is an accurate description of much of the forcible head shaving at the end of WW2.

57 Thom Brooks, 'Shame On You, Shame On Me? Nussbaum on Shame Punishment,' Journal of Applied Philosophy 25 (2008), pp. 322-34.

$5^{8}$ In the case of 'private' shaming, the standard is enforced only for the target, and not for any audience. 
standards loosely maps on to Wilfrid Sellars' distinction between ought-to-dos and ought-to-bes. ${ }^{59}$ Ought-to-dos are rules of action, i.e. norms. Agential shaming reinforces ought-to-dos. Ought-to-bes, in contrast, are rules of criticism, and assign values to certain states of affairs. The kinds of standards invoked by non-agential shaming look like ought-to-bes; for example, we shame women for menstruating because their bodies ought to be different from how they are; their bodies ought to be less disgusting. When someone engages in non-agential shaming, they make the target and the audience recognize that some particular standard has not been met. ${ }^{60}$

Thus, agential shaming and non-agential shaming, despite their differences, can both function to reinforce social meanings; agential shaming reinforces norms of behavior, and non-agential shaming reinforces social standards, i.e. general beliefs as to what is disgusting, what is ugly, etc. One might not think that social standards are the kinds of things that need enforcing; maybe they simply reflect natural responses to things that are genuinely disgusting or ugly. Yet social practices not only shape how we interact with each other, but also what we value and what we see as valuable. Often we are unaware of the ways in which social meanings infect our perceptual capacities; because we see things as valuable or non-valuable, we are inclined to believe that social meanings reflect the world as it really is, rather than making it the way it is. Yet social meanings are not permanent; they need to be maintained. Agential shaming functions to cement dominant conceptions of what is morally right and wrong, good and bad. Non-agential shaming, I suggest, functions to cement dominant conceptions of what is good and bad in less obviously moral senses, like what is ugly or disgusting. Both kinds of shaming function to tell the target and the audience either that 'these actions are wrong' or 'these properties are bad.' That is to say, they reinforce our commitment to social meanings.

Sometimes the social meanings enforced by shaming are oppressive; this seems particularly true of non-agential shaming. Non-agential shaming can function to mark out certain demographic groups as inherently inferior to others, and in so doing it can render members of those groups more submissive, by making them feel powerless and hopeless. For example, period shaming enforces society's commitment to the disgustingness of periods and in so doing it ostracizes and subjugates the group of people who have periods. It marks out this group as inferior, and it also renders its members more submissive by

59 Wilfrid Sellars, 'Language as Thought and as Communication,' Philosophy and Phenomenological Research 29 (1969), pp. 506-27, p.509.

6o Depending on one's preferred view of shame, the target's recognition that she has failed to meet some social norm or standard (even when her doing so is not something she could be 
encouraging them to feel ashamed about a natural feature of their bodies. In so doing, period shaming helps maintain gendered hierarchies. That said, that shaming can be oppressive is not the only reason why we might have reservations about the practice. We might agree with Nussbaum that shame, even in response to genuine wrongdoing, and even when experienced by privileged agents, is generally so paralyzing and dignity-undermining that shaming of any kind and of any person is always impermissible. ${ }^{61}$ I leave the important question of shaming's permissibility to future work.

\section{7}

\section{Conclusion}

I have argued that shaming takes two forms. Agential shaming involves holding the target morally responsible for some act or characteristic (i.e. blaming her) and inviting an audience to do so, too. Non-agential shaming is not a form of blaming, because it does not involve holding the target morally responsible. Rather, it likely involves the expression of an objective attitude like disgust towards the target, combined with an invitation to others to express similar attitudes.

This is a complicated picture, but it reflects the multifaceted nature of our evaluative interactions with each other. I have shown that shaming can be an enforcement tool for both norms and standards. Norms prescribe and proscribe behavior, and standards allocate values to different individuals, groups, and bodies. We are held to norms like 'do not steal,' but we are also held to standards according to which certain characteristics, like having a particular body type, are considered better than others. Shaming can enforce both social norms and social standards.

That shaming has two forms differentiates it from blaming, but it does not make it anomalous in the sphere of communicative practices. Praising can be similarly bifurcated. Praising is regarded by moral philosophers as a positive way of holding someone morally responsible, yet outside of philosophy we might describe the act of complimenting someone on her looks or natural talents as a kind of praising. These are characteristics for which she cannot claim moral responsibility, and we know this when we compliment her. Thus praising, at least in the ordinary language sense, can have both agential and

morally responsible for) could take the form of shame, qua a pained recognition that one has fallen short of social ideals.

61 Nussbaum, Hiding From Humanity. 
non-agential dimensions. I propose that we think of shaming as having a similar nature.

My account of shaming makes contributions both outside and inside philosophy. Outside of philosophy, I have shed some overdue light on a phenomenon which has been and continues to be subject to much discussion in popular culture. If we are to take a stance in debates on whether shaming should be encouraged, we must first be clear on the exact nature of the practice.

As for the account's philosophical implications, it calls on moral philosophers to recognize the important role that objective attitudes play in social life. Since Strawson's Freedom and Resentment, moral philosophy has often been conducted in a reactive attitude framework, and affective practices which do not involve responsibility ascription but which nonetheless evaluate people have been largely ignored. I have shown that it is time to pay these practices attention. Practices like shaming can sometimes involve reactive attitudes (and therefore ascriptions of moral responsibility), but sometimes they do not. Yet both kinds of shaming play an important role in reinforcing social meanings, and both can therefore play a key role in reinforcing oppressive social structures. In Freedom and Resentment, Strawson asks his reader to bear in mind 'what it is like to be involved in ordinary inter-personal relationships.' ${ }^{2}$ To do this properly we must take shaming, in both its agential and non-agential forms, more seriously.

\section{Acknowledgements}

I thank Rae Langton, Clare Chambers, Paulina Sliwa, Cathy Mason, Adam Bales, Thom Brooks, and two anonymous referees for this journal for their helpful feedback on earlier versions of this paper. My research was supported by a studentship from the Arts and Humanities Research Council.

\section{Biographical Note}

Lucy McDonald is a Research Fellow in philosophy at St John's College, University of Cambridge.

62 Strawson, Freedom and Resentment, p.7. 